Article

\title{
Renewable Energy Cooperation in Europe: What Next? Drivers and Barriers to the Use of Cooperation Mechanisms
}

\author{
Natàlia Caldés ${ }^{1}$, Pablo del Río ${ }^{2}$, Yolanda Lechón ${ }^{1, *}$ (D) and Agime Gerbeti ${ }^{3}[\mathbb{C}$ \\ 1 Centro de Investigaciones Energéticas, Medioambientales y Tecnológicas (CIEMAT), 28040 Madrid, Spain; \\ natalia.caldes@ciemat.es \\ 2 Institute for Public Policies and Goods (IPP), Consejo Superior de Investigaciones Científicas (CSIC), \\ 28037 Madrid, Spain; pablo.delrio@csic.es \\ 3 Department of Law, Economics, Politics and Mondern Languages, University of Roma, 00192 Lumsa, Italy; \\ a.gerbeti@lumsa.it \\ * Correspondence: yolanda.lechon@ciemat.es; Tel.: +34-913466383
}

Received: 12 November 2018; Accepted: 20 December 2018; Published: 27 December 2018

check for updates

\begin{abstract}
Cooperation on Renewable Energy Sources (RES) in Europe is expected to contribute to energy and climate policy goals and bring multiple benefits at the national, regional and European levels. For this reason, the Cooperation Mechanisms of the RES Directive 2009/28/EC were originally designed to encourage the collaboration of countries and contribute to the achievement of the $2020 \mathrm{EU}$ RES target in a cost-effective manner while providing Member States (MS) with flexibility to meet their national RES objectives. These mechanisms will allow MS to achieve their national RES target in cooperation with other MS and include statistical transfers, joint projects and joint support schemes. However, their use has been limited, leading to skepticism about their future use. The aim of this article is to identify the factors that influence MS decision to use the Cooperation Mechanisms and to rank their importance. The empirical analysis is based on a comprehensive, in-depth literature review and a dedicated survey to MS. Our results show that, indeed, a wide array of drivers and barriers have influenced and will influence the future use of the Cooperation Mechanisms. The main drivers and barriers in the past significantly differ to those influencing the future use. Furthermore, the perception of the relevance of the drivers and barriers by the MS differs depending on whether the countries have already met or are having difficulties to meet their 2020 RES target domestically and on whether they have actually used the Cooperation Mechanisms or not. Some policy implications on how to overcome the existing barriers to the use of those mechanisms are derived from the analysis.
\end{abstract}

Keywords: RES cooperation mechanisms; Governance 2030; opening of support schemes; renewable energy sources; drivers and barriers

\section{Introduction}

Renewable energy cooperation is expected to play an important role as a way to ensure an effective and affordable low-carbon energy transition in the EU, taking advantage of trade within the internal market, safeguarding security of energy supply, coordinating climate adaptation measures and optimizing the cost-effectiveness of actions [1]. It is for these reasons that Europe wants to promote a cooperative RES deployment where the resources are most abundant, where the overall system costs would be minimized (e.g., reduced need for backup, avoided grid investments, etc) or where overall social benefits would be maximized (e.g., increased security of supply, Green House Gas (GHG) emissions savings, avoided local air pollution, employment effects, innovation effects, etc) [2]. 
Back in 2009, the Renewable Energy Directive 28/2009/EC (also known as the RED) [3] defined an EU 20\% renewable (RES) target as well as national binding RES targets expressed as a percentage of RES on gross final energy consumption. Such targets were set based on a "flat rate approach" that only considered MS gross domestic product and their historical RES deployment. As a result, RES national targets were not necessarily correlated with MS RES potentials nor with their RES generation costs [4] and, thus, some MS with scarce RES resources or/and high renewable energy generation costs faced challenges to meet their interim targets domestically while for others-with abundant resources and/or cheaper generation costs- it was easy to meet theirs and even to overcomply.

In order to provide MS with more flexibility and achieve the EU target in a more cost-effective way, the Renewable Energy Directive (RED) set the legal framework for the use of cooperation mechanisms. These mechanisms will allow MS to achieve their national RES target in cooperation with other MS and include statistical transfers, joint projects and joint support schemes in which two MS (or one MS and another non-EU country in the case of joint projects with third countries) are involved. The aim of this article is to identify the factors that influence MS decision to use the Cooperation Mechanisms and to rank their importance. The empirical analysis is based on a comprehensive, in-depth literature review and a dedicated survey to MS.

While the Directive specified the general accounting rules of these mechanisms, their design and implementation was left to the cooperating MS [5]. MS could, depending on their needs and priorities, choose from the four possible Cooperation Mechanisms (Table 1):

Table 1. The Cooperation Mechanisms of the RES Directive.

\begin{tabular}{cc}
\hline Cooperation Mechanism (Article in the Directive) & Description \\
\hline Statistical transfers (Article 6) & $\begin{array}{c}\text { In this case, renewable energy (electricity, heat or transport energy) which has been } \\
\text { produced in one MS is virtually transferred to the RES statistics of another MS, } \\
\text { counting towards its national RES target. }\end{array}$ \\
Joint Projects between MS (Article 7 and 8) & $\begin{array}{c}\text { It allows EU MS to finance a RES project jointly, thus sharing the costs and benefits of } \\
\text { the project and developed under framework conditions jointly set by two or more MS } \\
\text { (i.e., a specific new plant is identified and the output of the plant is shared } \\
\text { (statistically) between two cooperating MS). The involved MS define which share of } \\
\text { the energy production counts towards which MS target. }\end{array}$ \\
Joint Projects with third countries (Article 9) & $\begin{array}{c}\text { Joint projects can also be implemented between MS and third (non-EU) countries. } \\
\text { A precondition is that an amount of electricity that equals the electricity amount } \\
\text { generated from RES and subject to this joint project is physically imported in the EU. }\end{array}$ \\
\hline Joint Support Schemes (Article 11) & $\begin{array}{c}\text { Under this scheme, MS merge or coordinate their RES support schemes and jointly } \\
\text { define how the renewable energy produced is allocated to their national targets. }\end{array}$ \\
\hline
\end{tabular}

As argued by [6] and [5], the three intra-European Cooperation Mechanisms provide opportunities for different depth, scope and duration of cooperation between MS as they all require different degrees of institutional changes., Once a specific cooperation mechanism has been chosen, it has to be properly designed in order to address the needs and particularities of the involved MS. The European Commission (EC) [7] and [8] provide MS with guidance in this respect.

In more recent pieces of EU legislation, regional cooperation is considered to be a fundamental instrument to guarantee an effective attainment of the Energy Union' goals in a cost-optimal manner. However, despite the important role that regional cooperation is expected to play in the 2030 framework, the way in which this cooperation is going to be encouraged and regulated is still under discussion. The proposed revised Renewable Energy Directive and the Energy Union Governance are the most relevant legislation pieces that will determine the way in which renewable energy cooperation will be articulated in the post 2020 time period.

The governance system in the Governance of the Energy Union and climate action [9] is expected to encourage enhanced regional cooperation and consultation as well as the exchange of information and best practices in a constructive dialogue between MS. The regulation also empowers the EC to request additional measures from MS in the event that there is a risk that the 2030 climate and energy goals are not being met. The new governance towards 2030 intends to use cooperation mechanisms also as one of the gap filling options to meet the RES national targets. An important challenge lies in 
the fact that the Governance regulation will have to compensate for the lack of national binding targets after 2020 .

As for the approved text of the revised Renewable Energy Directive proposal [10], article 5 indicates that "MS shall open support to generators located in other MS under the conditions laid down in this Article". A mandatory opening of support schemes was proposed for at least $10 \%$ of newly-installed capacity over 2021-2025 and 15\% over 2026-2030. Furthermore, it indicated that the allocation to MS of electricity supported through opened schemes shall be subject to a cooperation agreement "following the principle that energy should be counted towards the MS funding the installation". In contrast, the use of cooperation mechanisms (articles 8 to 12) still remains at MS discretion in the approved text of the RES directive. In fact, the contents of the articles related to those instruments remain unchanged, with the exception of article 8 on statistical transfer, which introduces the so-called European Union Renewable Development Platform, which is tool to facilitate the achievement of the EU target and the implementation of statistical transfers by matching the demand and offer of RES shares.

Furthermore, as a way to overcome MS coordination failures and encourage regional RES cooperation, a new instrument to support cross-border RES cooperation has recently been proposed as part of the Connecting Europe Facility (CEF), a key EU funding instrument to promote growth, jobs and competitiveness through targeted infrastructure investment at European level. [11]. The "Cross-border Renewables Projects" instrument fosters the Europeanization of renewable energy policy, underpinning the new EU level renewables target and the opening of support schemes as proposed by the Commission in the Renewables Directive and paving the way for further voluntary cooperation in the field [2]. Projects that meet the cross-border renewable energy eligibility criteria may receive financial support to conduct pre-feasibility analyses and, eventually, grants for work (Article 7 of the accompanying regulation [11].

There is currently a renewed interest in the cooperation mechanisms as the 2020 deadline on national RES targets approaches. However, it remains unclear how some countries which are well behind their RES targets will meet them. Furthermore, the cooperation mechanisms may be an alternative for MS to fulfill their national RES contributions. Indeed, and according to Eurostat (2018), some countries are not on track to meet their 2020 RES targets and, thus, could potentially be interested in using the cooperation mechanisms (so-called "off-taker countries"), whereas others (or "host countries") have renewable electricity production surpluses above their domestic RES target and, as such, could potentially become interested in trading their surplus through the use of those mechanisms (the former set of countries includes Latvia, Portugal, Slovenia, Spain, Greece, France, Germany, Slovakia, Cyprus, Ireland, United Kingdom, The Netherlands, Malta and Luxemburg, whereas potentially host countries include Sweden, Finland, Croatia, Estonia, Lithuania, Bulgaria, Italy and Czech Republic). Some MS have already implemented new RES support measures, which will likely help them meet their 2020 RES target domestically and even become potential host countries (for example, as a result of the renewable energy auctions organized in 2016 and 2017, 8 GW of RES have been awarded in Spain and it is expected that this country will meet its $20 \%$ target by 2020).

As demonstrated in several research projects (Beyond 2020: [12], Towards 2030: [13], Better: [14]), failure to adopt a cooperative approach when meeting the national or EU RES targets would translate into higher costs and/or lower benefits for European citizens. Additionally, these costs are expected to increase in the future when higher shares of RES lead to higher grid and integration costs, unless RES deployment is optimized across the EU. Furthermore, renewable energy cooperation may also contribute to other non-energy related policy goals such as EU cohesion through the creation of additional bonds between MS.

Nevertheless, despite the above mentioned benefits and initial expectations, barriers of heterogeneous nature have prevented a wide use of the Cooperation Mechanisms among MS, as demonstrated by their limited use since 2009. Statistical transfers (art. 6) have only been used twice (between Luxembourg and Lithuania and between Luxembourg and Estonia, both in 2017) and this is also the case with the joint support schemes of article 11 (the joint certificate scheme between Sweden 
and Norway in 2012 and the mutually opened PV auctions between Germany and Denmark in 2016). The other Cooperation Mechanisms (joint projects) have not been used at all.

Various studies have attempted to identify those factors (drivers and barriers) that may have influenced the decision to cooperate in the past and could partially explain the limited use of the Cooperation Mechanisms [5,6,8,14,15].

Refenrence [5] aims to identify the value proposition of solar exports in Europe in order to increase the awareness and support among decision makers and to explore options to make solar projects feasible. Among the barriers that currently prevent cross-border electricity trade, [5] focuses on two existing hurdles: the limited political support towards solar electricity exports in Europe and the financial gap between the electricity generation cost and the market pool price.

Refenrence [6] explores how regional cooperation could be fundamentally strengthened within the 2030 governance and how it can help to reach and exceed the $27 \%$ renewable energy target by 2030. The authors note that, despite the advantages, so far the Cooperation Mechanisms have not been applied mainly due to political, technical and legal barriers. A general overview of these barriers is provided, placing them according to whether Member States can easily address them, and according to their impact.

Refenrence [8] provides an analysis of current implementation and relevant design features of the Cooperation Mechanisms. Based on interviews with 14 EU Member States carried out in 2013 and a literature review it identifies the Member States engagement in cooperation mechanisms, barriers for a broader application of the Cooperation Mechanisms and potential remedies to overcome these barriers. According to the authors, the key obstacles to implement the Cooperation Mechanisms are the uncertainty of target compliance for Member States and the uncertainty of costs and benefits of cooperation. Other crucial barriers are the lack of public acceptance in the buying country, the first-mover risk of those countries that enter into cooperation first and the current lack of clarity on the governance framework of the post-2020 regulation for RES.

Reference [14] summarises the work done in the context of the BETTER project, which tried to identify cooperation mechanism opportunities between the EU and its neighboring countries. Drivers to use such mechanism for Europe include achieving RES and climate change targets more cost-efficiently, fostering economic relations with neighboring countries, benefits for domestic industry, diversifying energy portfolio \& supply regions, contributing to sustainable development of neighboring countries and getting flexible renewable power supply to complement own RES-E. Drivers for neighboring countries include attracting foreign investments in order to partially meet an increasing energy demand, creating new jobs and industrial opportunities, fostering technology and knowledge transfer, creating income from domestic resources, creating economic and political interdependencies with the EU, contributing to the decarbonisation of the domestic energy mix and creating economies of scale in RES-E deployment. However, [14] also identifies several challenges for RES-E trade, including underdeveloped legal and regulatory frameworks, weak grid infrastructures, lower than expected socio-economic benefits from RES deployment, high upfront costs and lack of financing mechanisms, high fossil fuel subsidies, current energy policy priorities in the EU and in neighboring countries not being conducive to the implementation of RES cooperation projects, electricity surplus in neighboring countries, limited demand and limited existing interconnections.

Jabobsen et al. [16] analyse the barriers for Cooperation Mechanisms and possible policy solutions through a literature review of papers published until 2012. In addition, the article analyses the importance of future RES targets for those mechanisms.

Finally, reference [15] aims to analyse the reasons for the absence of RES imports to the European Union, for which the authors develop a multi-level heuristic, which covers three sequential acceptance levels: political attractiveness (macro-level), the "business case" (micro-level) and civil society perspectives (public discourse level). The authors find out that numerous factors on all three levels determine the success/demise of RES trade. So far, trade has failed on the macro-level, because European policymakers perceive that targets can be achieved domestically with significant co-benefits 
and because exporter countries have rapidly increasing electricity demand, limiting the realisable exports. As policymakers deemed it unattractive, they did not implement policy-supported business cases. Whereas public opposition against trade has not been an issue. Potential cost savings has only been one among other determinants.

The most commonly reported drivers in the literature include: (i) lowering the costs of reaching the national 2020 RES targets, (ii) closing the potential gap between RES production and RES target and/or interim target, (iii) cooperating for technology development and (iv) promoting long term cooperation. Several barriers could partially explain the limited use of the Cooperation Mechanisms. For example, according to [6] the most relevant hurdles include: (i) social opposition (ii) lack of physical interconnections, (iii) discrepancy of electricity market design and specific rules for market access and operation of power plants across MS, (iv) regulated energy prices, (v) oligopolies (lack of realized competition), (vi) different RES support schemes across Europe which prevent a more efficient allocation of RES investments, (vii) MS disparities towards their preferred energy mix and their resistance to lose control over their energy policy. As to future potential barriers for renewable energy cooperation in Europe, country-specific barriers, coordination failures between MS and/or different stakeholders and currently limited tools at the EU level to ensure the collective 2030 EU RES target is met in a cost-effective way and to incentivize regional RES cooperation have been mentioned.

Although those contributions identify the drivers and barriers to the use of those mechanisms, and often some factors are stressed, it is not their aim to provide an explicit ranking of their relevance. This paper covers this gap in the literature. It collects the drivers and barriers which have been included in previous contributions but asks directly those which are directly responsible for their adoption, i.e., policy makers in off-taker and host countries about the relative importance, something which has not been attempted in the past. A notable exception is [6], which also interviews EU Member States. However, compared to this contribution, our article provides more up-to-date information (interviews have been carried out in 2018 vs. 2013) and also the coverage of countries is substantially greater (19 vs. 14 countries). It also analyses the MS responses according to two regulatory regimes (Renewable Energy Directive 28/2009/EC and the new revised Renewable Energy Directive for the post 2020 period), and takes into account the different drivers and barriers to distinct types of countries, i.e., whether the country plays a host or off-taker role and whether it has successfully engaged in a cooperation agreement or not.

The renewed interest and future expectations in renewable energy cooperation requires a more accurate analysis of the past experience as well as to the future role that the Cooperation Mechanisms may play in the construction of the Energy Union. For this purpose, it is necessary to look back, take advantage of the lessons learned and have a forward looking view of the new circumstances that will shape renewable energy cooperation in the future. To address these challenges, two research questions emerge: (i) What have been the main drivers and barriers to the use of the Cooperation Mechanisms in the past? and (ii) What are the expectations as to the main drivers and barriers to the use of the Cooperation Mechanisms beyond 2020? This article empirically assesses those drivers and barriers, providing a ranking of their importance and deriving policy recommendations which may activate those drivers or mitigate those barriers.

To address these research questions, this article goes one step forward and contributes to enlarge the existing body of knowledge around RES cooperation in several ways. First, compared to previous studies, the time period covered by this study is wider. As such, it considers new evidence of both failed and successful attempts to use the Cooperation Mechanisms in Europe. Furthermore, it also explores the future prospects for RES cooperation by considering the regulatory framework in the post 2020 period, something which has not been attempted in previous contributions. As a result of this wider and more recent evidence base, a larger list of potential drivers and barriers than in previous studies has been identified, analysed and categorized. Finally, and most importantly, the results of this work are based on a consultation with Member States which was undertaken in May 
2018 through a dedicated confidential survey questionnaire (see Appendix A) that was distributed to MS representatives during the CA-RES III (www.ca-res.eu) meeting that took in Warsaw in May 2018.

This article is structured as follows: the next section describes the methodological approach used to answer the research questions. The results of the analysis are provided in Section 3 and discussed in Section 4, linking them to potentially useful policy interventions. The paper closes with some concluding remarks.

\section{Materials and Methods}

In an attempt to answer the research questions, this work is based on three methodological steps:

Step 1: Identification of potential factors that may have influenced, either in a positive or negative way, Member States' use of the Cooperation Mechanisms of the Renewable Energy Directive from 2009 to 2018. To do so, a meta-analysis of the existing literature on RES cooperation has been conducted. Such extensive literature review included peer reviewed articles, relevant project reports and the grey literature. Additionally, other sources of information including semi-structured interviews with MS representatives as well as European authorities were conducted in the context of the CA-RES project meetings. As a result of this first step, more than forty factors were identified (see Section 3).

Step 2: Analysis and characterization of identified factors. Following a similar approach as [17], a set of classification criteria has been proposed based on the literature review, expert consultation and own judgment. As a result, and following [1], the considered factor categories have been defined as follows:

Political and policy factors would encompass those issues related to the Cooperation Mechanisms that matter for policy makers at the national, regional or local level and that would, in turn, affect their support or opposition towards the cooperation mechanisms. Note that given their relevance and distinctive nature, the economic and environmental issues that matter for policy makers have been classified separately into political-economic and political-environmental factors. In addition, issues related to policy features (uncertainty on the future policy framework, ambition of targets and design options to implement the Cooperation Mechanisms) have been included in this category.

Technical factors relate to the physical or technical restrictions or enablers that affect the successful implementation of the Cooperation Mechanisms. Among others, this category includes: improvement of system management through the import of dispatchable electricity, the possibility to foster technology and knowledge transfer, lack of market and grid integration, challenges in quantifying indirect associated costs and benefits, etc.

Legal factors refer to legal or regulatory barriers/drivers (such as regulatory gaps, trade barriers, potential legal challenges and planning restrictions). Specific relevant legal factors to the use of the Cooperation Mechanisms include: uncertainty on state aid compliance, heterogeneous regulated energy prices and support schemes across MS, obligation to open support schemes and lack of sanctions for non-compliance with 2020 RES targets.

Geopolitical factors relate to those issues that affect two or more countries in terms of political power, commercial relations, etc. Among others, this category includes: the possibility to foster political and economic relations with other MS, security of supply issues, the possibility to jointly test new support schemes, potential resistance from transit countries and "first-mover" risk/advantage.

Public acceptance factors relate to those factors that positively or negatively influence the social perception of the Cooperation Mechanisms. Such perception may determine the support or opposition of civil society, including voters, local residents and employees/labour unions, media and other opinion leaders. The interests of these groups, whose degree of acceptance can be a driver or a barrier to the use of the Cooperation Mechanisms, include soft institutions like norms and ethics. Media also plays a role in this group by shaping opinions and providing information to the public [18]. Examples of such factors are: public reaction in the off-taker country (i.e., due to investing tax-payers'money abroad), public reaction in the host country (i.e., due to the so-called ("Not in my backyard" (NIMBY) effect), public reaction in transit countries (visual impact of electricity grid), public perception of 
environmental benefits (i.e., decarbonisation) and public perception of socio-economic benefits (i.e., jobs and economic activity).

Finally, as mentioned before, within political factors, a distinction has been made between economic factors (such as cost savings in MS RES target achievement, generation of revenues from domestic resources, attraction of foreign investments to deploy domestic plants, new domestic jobs and industrial opportunities and costs savings at the EU level) and environmental/climate related factors (such as contribution to long term decarbonisation, alignment with the Paris Agreement objectives, climate leadership, etc).

Step 3: Present and future factor relevance assessment. As a way to assess the past and future importance of each one of the identified factors, a dedicated survey questionnaire (see Appendix A) was designed and filled by Member States representatives who were asked to answer the question: "How has each factor influenced the use of the Cooperation Mechanisms in your country?". For each factor displayed in Table 2, MS could choose from: -3 (very important barrier), -2 (important barrier), -1 (somehow important barrier), 0 (not relevant), 1 (somehow important barrier), 2 (important barriers) and 3 (very important barrier). The questionnaire was distributed through physical means (paper) to twenty eight Member States and one representative of the Energy Community during the Concerted Action on the Renewable Energy Directive (CA-RES) meeting that took place in Warsaw on April 25-26 2018. The CA-RES is an instrument of the Horizon 2020 Programme, which supports the transposition and implementation of the RES Directive. The results presented here are based on the answers from nineteen countries which were statistically analyzed using Excel and dynamic tables.

Confidence intervals have been calculated using the expression:

$$
\bar{X} \pm z^{*} \frac{\sigma}{\sqrt{n}}
$$

where $\bar{X}$ is the sample mean, $z^{*}$ the upper critical value that is equal 1.96 assuming a normal distribution and a $95 \%$ confidence level, $\sigma$ the population standard deviation (measured by the sample standard deviation) and $\mathrm{n}$ the sample size. Statistical significance has been tested using a Student's t-test and a $95 \%$ confidence level.

Table 2. Categorization of factors.

\begin{tabular}{c} 
Political Factors \\
Political support at the National level \\
about the design options to implement Coop. Mechs \\
Difficulties in communicating benefits \\
Uncertainty \\
Uncertainty about the post 2020 regulatory framework \\
Unambitious post 2020 RES targets \\
Political support at the regional level \\
Technical Factors \\
\hline Import/supply dispatchable/flexible RES (to improve system management) \\
Foster technology research and knowledge transfer \\
Contribute to improve tech. performance and cost reductions \\
EU guidance in implementing the Cooperation Mechanisms \\
Lack of market and grid integration \\
Challenges in quantifying indirect associated costs and benefits \\
Limited interconnection capacity between some MS \\
Legal Factors \\
Uncertainty on state-aid compliance \\
Obligation to open support schemes \\
Heterogeneous regulated energy prices and support schemes across MS \\
Lack of sanctions for non-compliance with 2020 RES targets
\end{tabular}


Table 2. Cont.

\begin{tabular}{|c|}
\hline Geopolitical Factors \\
\hline Foster political and economic relations with other MS \\
\hline Domestic industrial interests \\
\hline Improve security of supply (diversification of RES sources) \\
\hline Jointly test new support schemes \\
\hline Move towards creation of an internal energy market \\
\hline Potential resistance from transit countries \\
\hline Resistance to lose sovereignty and control over energy market \\
\hline "First mover risk" \\
\hline Public Acceptance Factors \\
\hline Public reaction in off-taker country (investing taxpayers money abroad) \\
\hline Public reaction in host country (NIMBY) \\
\hline Public reaction in transit country (visual impact of electricity grid) \\
\hline Public perception of environmental benefits \\
\hline Public perception of socio-economic benefits (jobs, econ activity, etc) \\
\hline Public perception of Energy Security issues \\
\hline Public perception of pro-European values (cooperation, integration, etc) \\
\hline Economic Factors \\
\hline Cost savings in MS target achievement \\
\hline Generate revenues from domestic resources \\
\hline Attract foreign investments to deploy domestic plants \\
\hline New domestic jobs and industrial opportunities \\
\hline Cost savings at the EU level \\
\hline Oligopolies (lack of realized competition) \\
\hline Environmental Factors \\
\hline Contribute to the long term decarbonization of the energy mix \\
\hline Alignment with Paris Agreement objectives \\
\hline Climate Leadership \\
\hline $\begin{array}{l}\text { Access to finance under the EU sustainable Finance Action Plan } \\
\text { Public concern for climate change as a foreign policy priority }\end{array}$ \\
\hline
\end{tabular}

\section{Results and Discussion}

In this section, the results from the analysis of the answers to the survey questionnaire are presented. First, forty four identified factors will be presented and classified into seven broader categories (3.1). Next, the following sub-sections will present the analysis of the MS answers to the survey questionnaire on the relevance of specific drivers and barriers to the use of the Cooperation Mechanisms, distinguishing between the past (2009-2020) and future periods (3.2), host versus off-taker countries (3.3) and successful versus non-successful countries (3.4).

\subsection{Identification and Characterization of Factors}

The first two methodological steps have resulted in a list of more than forty factors which have been classified according to seven categories which are described in Table 2 below: (i) political factors, (ii) technical factors, (iii) legal factors, (iv) geopolitical factors, (v), public acceptance factors, (vi) economic factors and (vii) environmental factors. Some factors will always negatively affect MS decision to cooperate regardless of the country role (for example, the difficulties in communicating benefits from cooperation to citizens or difficulties in quantifying indirect costs and benefits) whereas other factors will always have a positive impact (such as the possibility to foster economic relations with the other cooperating countries). In contrast, some factors will impact differently depending on the country role. For example, the possibility to reduce costs in MS target achievement will be relevant for off-taker countries, whereas it will not be relevant for transit or host countries. 


\subsection{General Trends: Past and Future}

Consulted MS representatives have been asked to assess, based on their best knowledge of the future regulatory and market conditions, the importance that the various factors have had and will have in the use of the Cooperation Mechanisms.

Figure 1 shows the average score by category for the periods 2009-2020 and post-2020. Regarding the past drivers and barriers, the results show that there have been more barriers than drivers influencing the use of the Cooperation Mechanisms (as shown by the higher number of factor categories to the left than to the right of the axis but also by the higher negative values). This result could partially explain the limited uptake of the Cooperation Mechanisms. Among the categories that negatively influence MS decision to cooperate, legal, political, public acceptance and geopolitical factors stand out (in that order). On the other side, the categories that appear to have positively influenced MS decision to cooperate include environmental and economic factors.

In contrast to the past, drivers are given higher scores than barriers as factors influencing the future use of these mechanisms, which brings some optimism about their relevance and use in the future. Public acceptance factors keep on being barriers (in fact, the single barriers). In contrast, factors which were barriers in the past are expected to be drivers in the future (technical, political, legal and geopolitical). The relevance of environmental and economic factors as drivers will significantly increase in the future compared to the past, when they were also perceived as drivers.

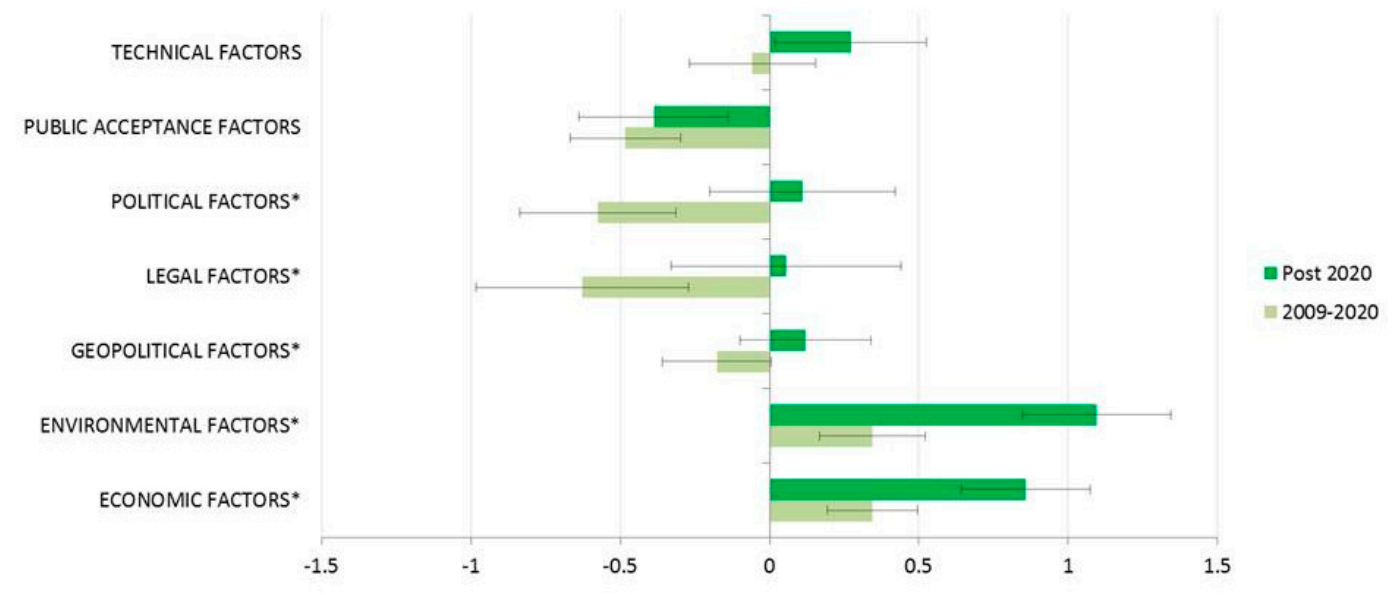

Figure 1. Average results of the survey questionnaire by factor category. Source: Own elaboration. The end of the bars indicate observed means and the horizontal line segments ("error bars") represent the confidence intervals around them. Categories of factors with an * are those for which significant differences have been found.

Complementary to this aggregate information, Appendix B provides the average score for each (disaggregated) factor in the past and the future. To facilitate the analysis, barriers have been coloured in red and drivers in blue. Regarding the past drivers and barriers, a higher number and longer red lines (barriers) than blue ones (drivers) can be observed, indicating the more intensive role played by the former compared to the later. The top five barriers to cooperation in the past include: (i) public reaction in off-taker countries (investing taxpayers money abroad), (ii) Heterogeneous regulated energy prices and support schemes, (iii) Difficulties in communicating the benefits of cooperation, (iv), Resistance to lose sovereignty and control over national energy market and (v) Uncertainty about the design options to implement the Cooperation Mechanisms. Some of these barriers will continue to be very relevant in the future (resistance to lose sovereignty, difficulties in communicating benefits and public reaction in off-taker countries), the relative importance of others is reduced (heterogeneous regulated energy prices and support schemes and uncertainty about the design options to implement the Cooperation Mechanisms) and yet others join the list of most relevant in this timeframe (public 
reaction in host country and transit country). This stickiness of some barriers indicates potential points for policy intervention. Basically, these results indicate the relevance of the government and public acceptance issues in the three types of countries involved (host, off-taker and transit) as well as the lower relevance of legal issues in the future. This trend may be explained because of the increased maturity of these mechanisms, the provision of further guidelines by the EU as well as some countries' practical implementation that show the direction and provide lessons to others.

The top five enablers in the past include: (i) cost savings in MS target achievement, (ii) contribution to improve technology performance and cost reductions, (iii) EU guidance in implementing the Cooperation Mechanism (iv) new domestic jobs and industrial opportunities and (v) move towards the creation of an internal energy market. In the future, the first four drivers remain very relevant, the last one loses relative importance and two other legal and environmental factors appear at the top of the list (namely obligation to open support schemes and access to finance under the EU sustainable Finance Action Plan). These results suggest that economic and environmental factors will be critical as drivers for the use of these mechanisms.

\subsection{Host and Off-Taker Country Views}

Identifying the different answers obtained by those countries that have a renewable energy surplus (and, thus, could be potential host countries) versus those countries that are facing difficulties in meeting their 2020 RES target domestically (and, thus, could potentially play an off-taker role in a cooperation agreement) provides additional insights. Such distinction has been made based on the progress reports from Eurostat (2018). This analysis could be policy-relevant since it would allow suggesting policy interventions in order to activate drivers or mitigate barriers to the use of the Cooperation Mechanisms which are specifically targeted at either potential host or off-taker countries.

The results displayed in Figure 2 show that most factor categories play the same role (either as a barrier or as a driver) independently if the country is a host or an off-taker country. However the intensity of the effect could be different. For the driver categories (economic and environmental factors), economic factors are more relevant for host countries while environmental factors are generally perceived as more important for off-taker countries. As for the barriers, legal and public acceptance factors are more relevant for off-taker countries than they are for host countries, whereas the opposite is true regarding political barriers. The only category for which there is a difference in the sign (direction) among host and off-taker countries is technical factors. For host countries, technical factors are regarded as a barrier while for off-takers they are perceived as not relevant.

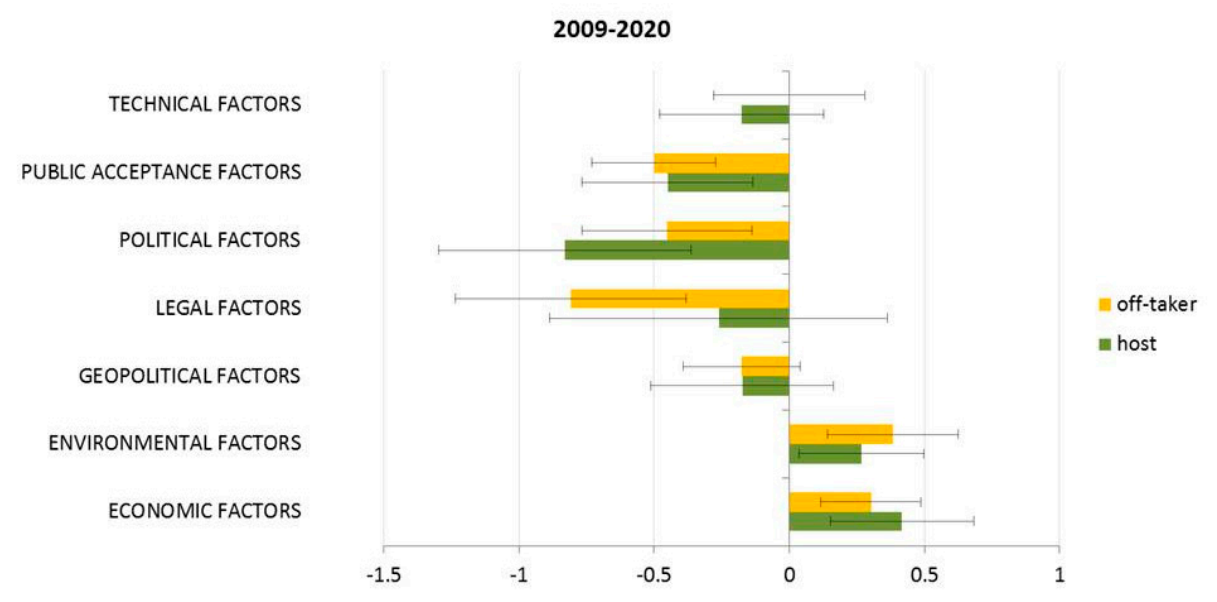

Figure 2. Factor relevance per category for off-taker and host countries (past). Source: Own elaboration. The end of the bars indicate observed means and the horizontal line segments ("error bars") represent the confidence intervals around them. No significant differences have been found. 
The picture changes slightly regarding the perception of future drivers and barriers (Figure 3). In the case of off-taker countries, all factor categories (except public acceptance factors) act as drivers, which suggest some optimism about the potential to use these mechanisms in the future. In the case of host countries, political factors are also seen as barriers, indicating that addressing political factors should be a main priority to encourage their implementation. Interestingly, legal factors are not found relevant by off-taker countries.

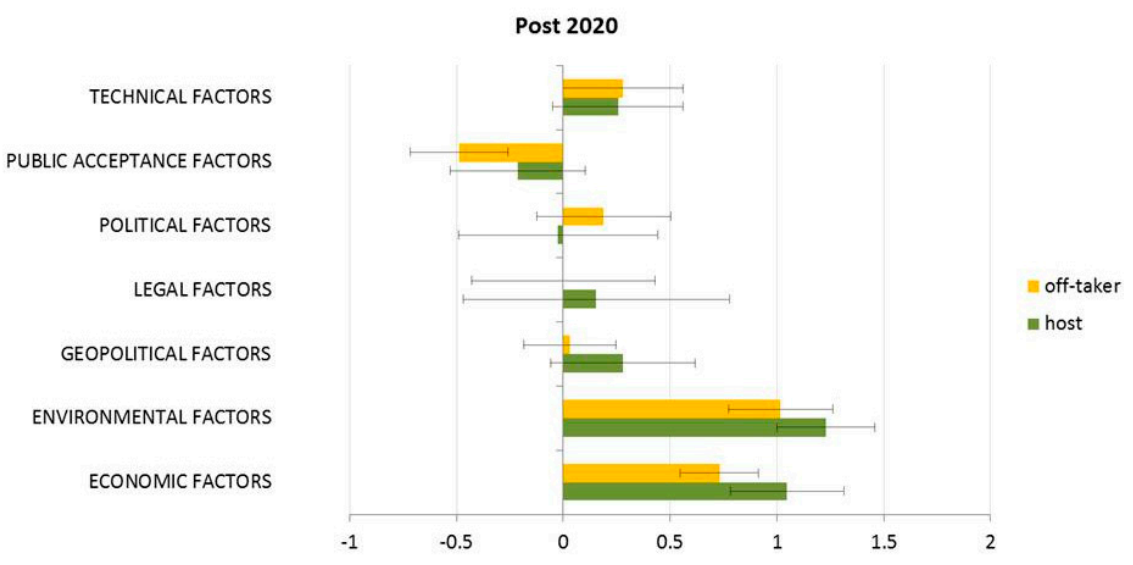

Figure 3. Factor relevance per category for off-taker and host countries (future). Source: Own elaboration. The end of the bars indicate observed means and the horizontal line segments ("error bars") represent the confidence intervals around them. No significant differences have been found.

A closer look at the most relevant disaggregated factors (see also Appendix B) in the past and the future shows differences for both types of countries. Top 5 drivers in the past are very different for both types of countries, except for cost savings in MS target achievement, and contribution to improve technology performance and cost reductions which are the only common highly relevant drivers for both host and off-taker countries. However, the other most relevant drivers for host countries include access to finance under the EU sustainable Finance Action Plan, domestic industrial interests and obligation to open support schemes. This ranking differs from those of off-taker counties which include: EU guidance in implementing the Cooperation Mechanisms, contribution to the long term decarbonization of the energy mix and move towards creation of an internal energy market. Some of these drivers keep on being relevant in the future: obligation to open support schemes and contribution to improve technology performance and cost reductions for both type of countries, cost savings in MS target achievement and access to finance under the EU Sustainable Finance Action Plan for host countries and EU guidance in implementing the cooperation mechanisms and contribute to the long term decarbonization of the energy mix for off-takers. Other drivers appear to be particularly relevant in this timeframe: New domestic jobs and industrial opportunities for host countries and obligation to open support schemes, access to finance under the EU Sustainable Finance Action Plan and alignment with Paris Agreement objectives for off takers.

Regarding the barriers in the past, two are very relevant for both types of countries in this timeframe (public reaction in off-taker country due to investing taxpayers money abroad and difficulties in communicating benefits), whereas others are specific to the host country (resistance to lose sovereignty and control over energy market, political support at the regional level and political support at the national level) or the off-taker country (heterogeneous regulated energy prices and support schemes across MS, uncertainty about the design options to implement Cooperation Mechanisms and uncertainty on state aid compliance). Some of those barriers are also deemed relevant for the future: resistance to lose sovereignty and control over energy market, difficulties in communicating benefits and public reaction in off-taker country (investing taxpayers money abroad) (for hosts), and heterogeneous regulated energy prices and support schemes across MS, difficulties in 
communicating benefits and public reaction in off-taker country (for off-takers). Others appear to be most relevant in the future for off-takers: public reaction in host country (NIMBY), public reaction in transit country (visual impact of electricity grid) for host countries and potential resistance from transit countries and public reaction in host country (NIMBY).

\subsection{Successful and Non-Successful Countries Views}

Most factor categories are also perceived differently (either as barriers or as drivers) depending on whether the country has been successful or not in the use of the cooperation mechanisms (Figures 4 and 5). Technical, political and geopolitical factors have been regarded as drivers by successful countries in the past, whereas they are considered as barriers by non-successful ones. Public acceptance and legal factors are perceived as barriers by both, although their intensity is greater for non-successful countries, especially in the case of political factors. Environmental and economic factors are seen as drivers, with a greater intensity for successful countries, especially in the case of economic factors.

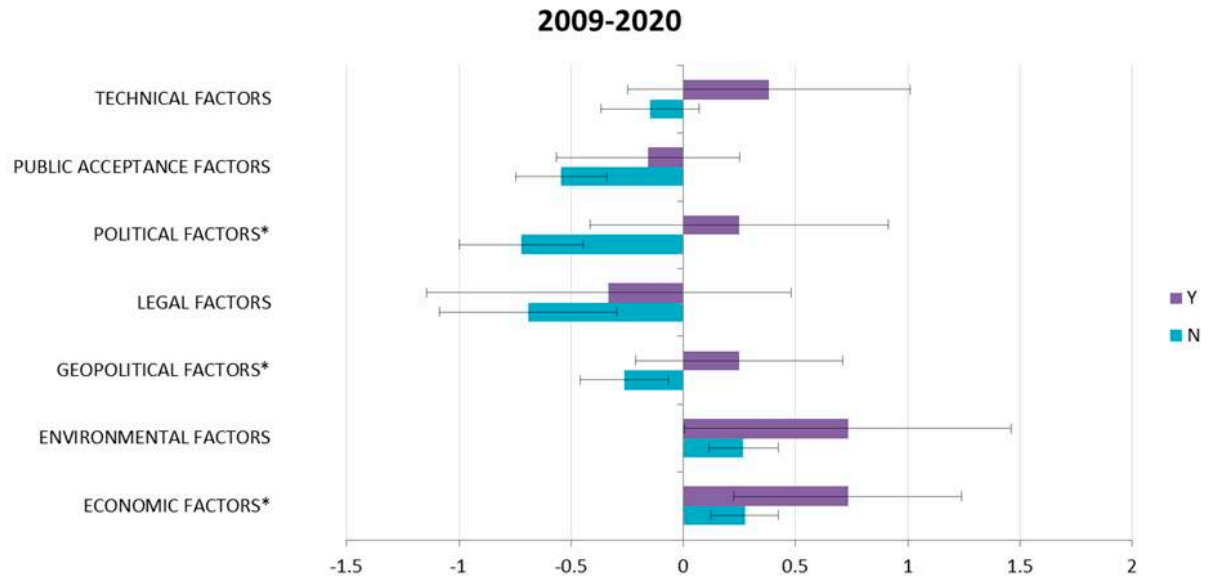

Figure 4. Factor relevance per category for successful and non-successful countries (past). Source: Own elaboration. The end of the bars indicate observed means and the horizontal line segments ("error bars") represent the confidence intervals around them. Categories of factors with an * are those for which significant differences have been found.

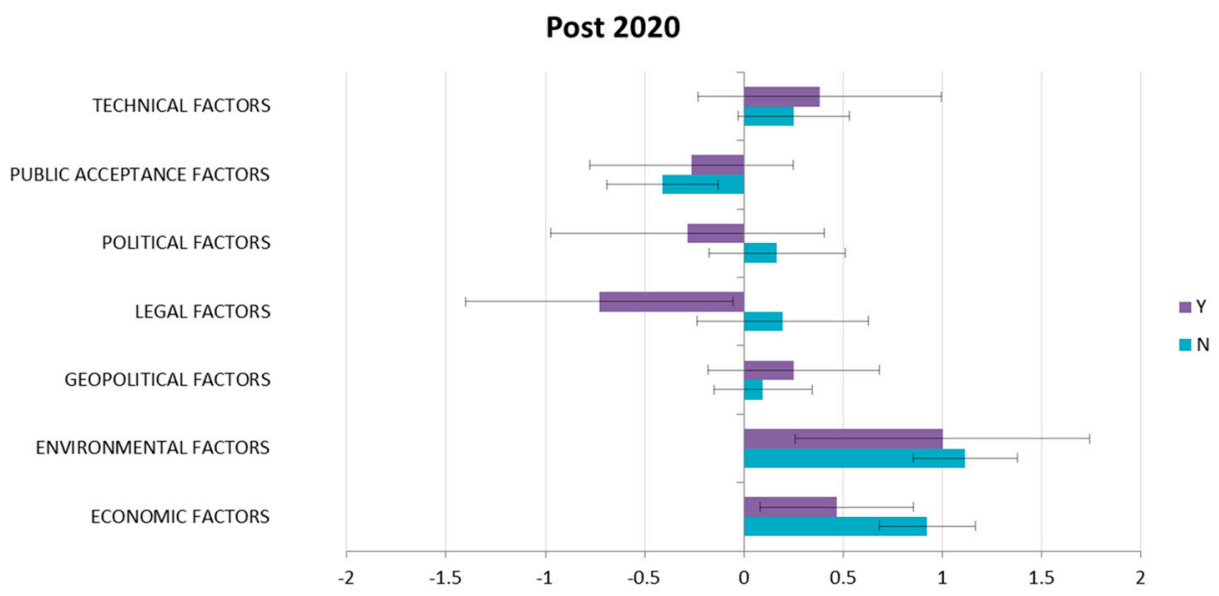

Figure 5. Factor relevance per category for successful and non-successful countries (future). Source: Own elaboration. The end of the bars indicate observed means and the horizontal line segments ("error bars") represent the confidence intervals around them. No significant differences have been found.

Some specific drivers and barriers are particularly relevant for one type of country, either in the past or the future (see also Appendix B). Regarding the 2009-2020 period, differential drivers for non-successful 
countries (i.e., with a greater relative importance) include new domestic jobs and industrial opportunities and access to finance under the EU Sustainable Finance Action Plan. Differential drivers for successful countries include cost savings at the EU level and obligation to open support schemes. Concerning the differential barriers for non-successful countries, heterogeneous regulated energy prices and support schemes across MS, difficulties in communicating benefits, resistance to lose sovereignty and control over the energy market and uncertainty about the design options to implement the Cooperation Mechanisms stand out. Differential barriers for successful countries include: "First mover risk", uncertainty on state aid compliance, heterogeneous regulated energy prices, support schemes across MS and import/supply dispatchable/flexible RES (to improve system management).

Looking ahead to the period after 2020, legal (heterogeneous regulated energy prices and support schemes across MS) and political factors (uncertainty about the design options to implement Cooperation Mechanisms) seem to lose importance as barriers, while public acceptance factors (public reaction in transit country and public reaction in host country) increase their relevance for non-successful countries. Regarding the successful countries, geopolitical factors such as the "first mover risk" and technical factors (import/supply dispatchable/flexible RES to improve system management) are not so relevant as barriers, whereas public acceptance problems such as public reaction in host country (NIMBY) and political factors related to difficulties in communicating benefits become more relevant. As long as the future drivers are concerned, non-successful countries consider that the obligation to open support schemes is the most relevant driver while successful countries start to see the geopolitical factors (foster political and economic relations with other MS and move towards creation of an internal energy market) as relevant drivers for the implementation of Cooperation Mechanisms.

\section{Discussion and Policy Recommendations}

Our results suggest that a wide array of drivers and barriers influence the use of the Cooperation Mechanisms. Considerable differences have been identified with respect to the relevance of specific drivers and barriers for the past and future use. Perceptions on their relevance also differ depending on the features of countries, i.e., whether they are potential hosts or off-takers and whether they have been involved in these mechanisms in the past or not. Overall, our results confirm the importance attached to some factors (drivers and barriers) in the literature. It stresses the importance of political and economic factors (as in [5]), political, technical and legal factors (as in [6]) and political, economic, public acceptance and geopolitical factors (as in [8]) In particular, our result about the importance of the geopolitical factor "first-mover risk" is in line with the findings in [8]. However, it also shows differing results. Our contribution highlights the importance of public acceptance barriers (in contrast to [15]) and gives a very relevant role to the environmental drivers, particularly in a post 2020 timeframe. However, our results are not strictly comparable with those in the literature, since the most remarkable added value of this work is that it ranks the drivers and barriers based on the actual answers from MS, something which has not been attempted in the past (with the exception of [8]) and that it considers very specific drivers and barriers in two different timeframes and for different countries, providing an original contribution in this regard. Overall, these results suggest that all factor categories play an influential role in this context and that most disaggregated factors either have been or will be drivers and barriers to the use of Cooperation Mechanisms. The disaggregated factors are more policy relevant than the aggregated ones, since they allow tying policy interventions to specific drivers or barriers. Indeed, our findings indicate key points for policy intervention. A diverse palette of options will be needed to either activate drivers or mitigate barriers. In short, a policy mix will be required.

Policies will probably need to be implemented at two different policy levels, i.e., they should include appropriate framework conditions and specific instruments. Different government levels (EU, national and regional) may be relevant for specific drivers and barriers. It should be taken into account that some drivers and barriers may not be easily tackled by policies (e.g., contribution to improve technological performance and cost reductions). In this case, the policy recommendations are rather limited. 
Taking into account the drivers and barriers to the use of Cooperation Mechanisms, specific instruments can be considered. They can be grouped in six main categories:

(1) Information provision. MS ask for guidance from EU institutions in order to implement the Cooperation Mechanisms. There is thus a key role to be played by the EU in providing guidance, information and know how regarding the use of these mechanisms. Furthermore initiatives like the Concerted Action (CA-RES) where MS representatives share their experiences and lessons learned regarding, among other topics, the use of the Cooperation Mechanisms has been reported to be very useful by MS representatives.

(2) Legislative initiatives. Some measures at EU level may address influential factors by making specific requirements to MS through the passing (or agreement) of legislation. For example, our results show that a key driver is "obligation to open support schemes". Further efforts at passing legislation which is directed to open these support schemes can be recommended.

(3) Access to finance. An important driver in our results is "access to finance under the EU sustainable Finance Action Plan". Therefore, continuation of the provision of such finance is a relevant measure to encourage the use of the Cooperation Mechanism. Another example of such type of support is the one offered by the "cross-border renewables projects" instrument of the Connecting Europe Facility [11].

(4) Public awareness campaigns. In addition to measures taken at the EU level, some useful policy interventions may also be adopted at the national and regional levels. This is the case with public awareness campaigns which are oriented towards a better communication of benefits. These campaigns would mitigate the public acceptance barrier related to investing taxpayer money abroad and could encourage political support at the national and regional levels.

(5) International cooperation. For example, "jointly test new support schemes" proves to be a relevant driver in our results. This can be supported at either the EU or national levels.

Finally, some drivers and barriers suggest broader types of policies which are taken for other reasons, or are part of general policy decisions, but which would indirectly have a positive effect on the use of the Cooperation Mechanisms, because they either activate a driver or mitigate a barrier. There are many examples of this: better interconnections between MS, more ambitious post-2020 RES targets, climate leadership, move towards the creation of an internal energy market, alignment with Paris Agreement objectives, more certainty about the post 2020 regulatory framework and "resistance to lose sovereignty and control over energy market".

Table 3 summarizes the aforementioned policy assessment, indicating the suitability of different types of policy interventions for distinct disaggregated factors. Based on the discussion above, we consider here two types of policy interventions: direct and indirect. The table shows which drivers and barriers can be activated or mitigated with the implementation of specific instruments (direct intervention, columns 3 to 7). It also shows which indirect policy interventions could be effective to tackle specific drivers and barriers (last column). Note that those drivers and barriers for which we do foresee neither a direct nor an indirect policy intervention. Thus, those for which policy intervention to activate a driver or remove a barrier is limited, are not shown in the table. These mostly refer to the economic and technical drivers and barriers.

Finally, the relevance of the drivers and barriers differs for distinct types of countries (e.g., host vs. off-taker and successful vs. non-successful ones). Therefore, it may make sense to propose policy measures which are specifically targeted at given drivers and barriers in different types of countries in order to induce their participation in the Cooperation Mechanisms.

The results of our analysis suggest that four instruments would be appropriate to encourage off-taker countries participation (information provision (EU guidance), opening support schemes in MS to other MS, access to finance and awareness raising campaigns) and also that measures with indirect effects would be supportive. 
Table 3. Relevant policy interventions for each disaggregated factor. Source: own elaboration.

\begin{tabular}{|c|c|c|c|c|c|c|c|}
\hline \multirow[b]{2}{*}{ Factor Category } & \multirow[b]{2}{*}{ Disaggregated Factors } & \multicolumn{5}{|c|}{ Direct Policy Measures (Specific Instruments) } & \multirow[b]{2}{*}{$\begin{array}{l}\text { Indirect Policy } \\
\text { Measures }\end{array}$} \\
\hline & & $\begin{array}{l}\text { Information } \\
\text { Provision }\end{array}$ & $\begin{array}{l}\text { Legislative } \\
\text { Initiatives }\end{array}$ & $\begin{array}{l}\text { Access to } \\
\text { Finance }\end{array}$ & $\begin{array}{l}\text { Public Awareness } \\
\text { Campaigns }\end{array}$ & $\begin{array}{l}\text { Int. } \\
\text { Coop. }\end{array}$ & \\
\hline Environmental & $\begin{array}{l}\text { Access to finance under the EU sustainable Finance Action Plan } \\
\text { Alignment with Paris Agreement objectives } \\
\text { Climate leadership }\end{array}$ & & & $\sqrt{ }$ & & & $\begin{array}{l}\sqrt{ } \\
\sqrt{ }\end{array}$ \\
\hline Geopolitical & $\begin{array}{c}\text { "First mover risk" } \\
\text { Jointly test new support schemes } \\
\text { Move towards creation of an internal energy market } \\
\text { Potential resistance from transit countries } \\
\text { Resistance to lose sovereignty and control over energy market }\end{array}$ & $\sqrt{ }$ & & & $\sqrt{ }$ & $\sqrt{ }$ & $\begin{array}{l}\sqrt{ } \\
\sqrt{ }\end{array}$ \\
\hline Legal & $\begin{array}{c}\text { Lack of sanctions for non-compliance with } 2020 \text { RES targets } \\
\text { Obligation to open support schemes } \\
\text { Uncertainty on state aid compliance }\end{array}$ & $\sqrt{ }$ & $\sqrt{ }$ & & & & $\sqrt{ }$ \\
\hline Political & $\begin{array}{c}\text { Difficulties in communicating benefits } \\
\text { Political support at the National level } \\
\text { Political support at the regional level } \\
\text { Unambitious post } 2020 \text { RES targets } \\
\text { Uncertainty about the design options to implement Coop. Mechs } \\
\text { Uncertainty about the post } 2020 \text { regulatory framework }\end{array}$ & $\sqrt{ }$ & & & $\begin{array}{l}\sqrt{ } \\
\sqrt{ } \\
\sqrt{ }\end{array}$ & & $\begin{array}{l}\sqrt{ } \\
\sqrt{ }\end{array}$ \\
\hline Public acceptance & $\begin{array}{l}\text { Public perception of energy security issues } \\
\text { Public perception of environmental benefits } \\
\text { Public perception of pro-European values } \\
\text { Public perception of socio-economic benefits } \\
\text { Public reaction in host country (NIMBY) } \\
\text { Public reaction in off-taker country (taxpayers money abroad) } \\
\text { Public reaction in transit country (visual impact of elect. grid) }\end{array}$ & $\sqrt{ }$ & & & $\begin{array}{l}\sqrt{ } \\
\sqrt{ } \\
\sqrt{ } \\
\sqrt{ } \\
\sqrt{ } \\
\sqrt{ } \\
\sqrt{ }\end{array}$ & & \\
\hline Technical & $\begin{array}{l}\text { EU guidance in implementing the Cooperation Mechanisms } \\
\text { Limited interconnection capacity between some MS }\end{array}$ & $\sqrt{ }$ & & & & & $\sqrt{ }$ \\
\hline
\end{tabular}


Compared to those policies, suitable measures to encourage host country involvement would only be marginally different to those four measures, although some noticeable differences can be observed. For example, regarding EU guidance, this would be enhanced in the case of host countries, because the barrier "uncertainty about the design options to implement Cooperation Mechanisms" is perceived as more relevant for these countries compared to off-takers. Public reaction in host, off-taker and transit countries are equally relevant barriers from a host country perspective, whereas public reaction in the off-taker country is clearly the most relevant for an off-taker country. This means that, from a host country perspective, it would be particularly important to enhance public acceptance in the three types of countries (host, off-taker and transit) rather than only in the off-taker. Furthermore, an additional instrument would be useful to encourage host country involvement (international cooperation/jointly test new support schemes). Finally, in addition to public support at the EU and national levels, policies at the regional level (political support) would be quite relevant in this case.

The analysis of the factors influencing involvement in the Cooperation Mechanism for successful and non-successful countries also provides interesting, policy-relevant insights. In this case, the focus of policies should be on factors which have actually shown a crucial influence on behavior, i.e., in the involvement or non-involvement in these mechanisms and which are also likely to have an influence in the future: drivers for successful countries and barriers for non-successful ones. Policies for successful countries which would activate key drivers would be EU guidance, access to finance and policies with an indirect impact. For non-successful countries, policies should aim to tackle the main barriers, which include public reaction in the host country (NIMBY), difficulties in communicating benefits, uncertainty on state aid compliance and heterogeneous energy prices and support schemes. Thus, public awareness campaigns, information provision (EU guidance) and indirect measures seem to be particularly relevant to remove barriers to the involvement of non-successful countries.

\section{Conclusions}

The Cooperation Mechanisms of the Renewable Energy Directive 28/2009/EC were originally designed to grant MS with more flexibility to meet their 2020 RES targets while contributing to reach the EU 20\% RES target in a cost-effective manner. Despite the initial expectations, the use of the Cooperation Mechanisms has been very limited since 2009. As of today, only four Cooperation Mechanisms have been implemented in Europe (under article Articles 11 and 6) and none with neighboring countries (Article 9 of the Directive). Besides cost savings in meeting the RES targets, multiple factors determine Member States willingness to engage in a cooperation agreement which may partially explain the limited use of the Cooperation Mechanisms during the 2009-2020 time period.

In this context, the purpose of this work has been to identify and assess the range of factors that may have influenced the use of the Cooperation Mechanisms in the past and to provide a ranking of the relevance of those factors in the past and the future. To achieve this goal, a literature review and an expert consultation have been conducted to identify and characterize both drivers and barriers to cooperation in the past. Next, based on the Member States' answers to a specially designed survey questionnaire, it has been possible to assess the actual importance of such factors in both timeframes.

As a result of the literature review and expert consultation, more than forty factors have been identified as having influenced MS decision to engage in a cooperation agreement. An assessment of the relevance of specific factors has been carried out, and specific drivers and barriers to the use of the Cooperation Mechanisms in both time frames (past and future) and for different types of countries (host vs. off-takers and successful vs. non-successful) have been identified. Next, policy implications deriving from such analysis have been discussed.

In the past, the number and intensity of barriers has dominated those of drivers, which could partially explain the limited uptake of the Cooperation Mechanisms. Among the categories that negatively influenced MS decision to cooperate, legal, political, public acceptance and geopolitical factors stood out (in descending order). On the other side, the categories that appear to have positively influenced MS decision to cooperate include environmental and economic factors. In contrast to 
the past, drivers are given higher scores than barriers as factors influencing the future use of these mechanisms, which bring some optimism about their relevance and use in the future. Public acceptance factors continue to be barriers (in fact, the single barriers) in this timeframe. In contrast, factors which were barriers in the past are expected to be drivers in the future (technical, political, legal and geopolitical). The relevance of environmental and economic factors as drivers will increase in the future compared to the past, when they were also perceived as drivers.

When assessing the differences between those countries that have a RES surplus (potential host countries) and those countries that have a RES deficit (potential off-taker countries), results show that most factor categories play the same role (either as barrier or as a driver) independently if the country is a host or an off-taker country. However the intensity of the effect is different. For the driver categories (economic and environmental factors), economic factors are more relevant for potential host countries whereas environmental factors play a more important role for off-taker countries. As for the barriers, legal and public acceptance factors are more relevant for off-taker countries than they are for host countries. In contrast, political and geopolitical barriers are more relevant for host countries than for off-taker countries. Technical factors is the only category for which there is a significant difference (in direction) between host and off-taker countries. For host countries, technical factors constitute a barrier while for off-takers they are a driver.

Finally, when assessing the different answers from those countries that have actually engaged in a cooperation agreement versus those countries that have not, some interesting results emerge. Most factor categories are perceived differently (either as barriers or as drivers) depending on whether the country has been successful or not in the use of the cooperation mechanisms. Technical, political and geopolitical factors have been perceived as drivers by successful countries in the past, whereas they are regarded as barriers by non-successful ones. Public acceptance and legal factors are seen as barriers by both, although their intensity is greater for non-successful countries. Environmental and economic factors are considered as drivers (both in the past and the future), with a greater intensity for successful countries whereas public acceptance factors are considered as barriers by both.

The results presented in this article are expected to shed some light on the complexity and number of reasons that explain the limited use of the Cooperation Mechanisms and contribute to suggest the implementation the measures needed to overcome the barriers in order to foster renewable energy cooperation in the future. In this regards, our results suggest that different types of policy interventions, i.e., a policy mix, will be needed in order to either activate the drivers or mitigate the barriers to the use of Cooperation Mechanisms for RES. Two types of policy interventions have been identified: specific instruments and indirect policy measures, and each has been tied to a given driver and barrier. Furthermore, the distinct relevance of different policy measures for different types of countries has been assessed.

Some limitations of this analysis are worth mentioning, suggesting avenues for future research. First, those factors (whether drivers or barriers) are likely to interact between each other. This analysis has considered them in isolation. Further efforts should focus on the investigation of those interactions. Second, although an effort has been made to tie specific policy interventions to drivers and barriers, policy measures which will be needed to activate those drivers or mitigate the barriers at different administrative levels have not been discussed in detail. Further research should thus be devoted to provide more details on the policy measures, as well as their design elements, which could be particularly useful in this context.

Author Contributions: Conceptualization: N.C., P.d.R., Y.L., A.G.; Methodology: N.C., P.d.R., Y.L., A.G.; Formal Analysis: Y.L.; Writing—Original Draft Preparation: N.C., P.d.R., Y.L., A.G.; Writing—Review \& Editing: N.C., P.d.R., Y.L., A.G.

Funding: This research was funded by H2020 MUSTEC project (www.mustec.eu). Funding from the European Union's Horizon 2020 research and innovation program under grant agreement No. 764626.

Acknowledgments: The authors would like to thank the participants of the CA-RES /CT1 meeting in Warsaw (May 2018) for their valuable contributions as well as insights provided by other members of the MUSTEC project.).

Conflicts of Interest: The authors declare no conflict of interest. 


\section{Appendix A. Survey Questionnaire}

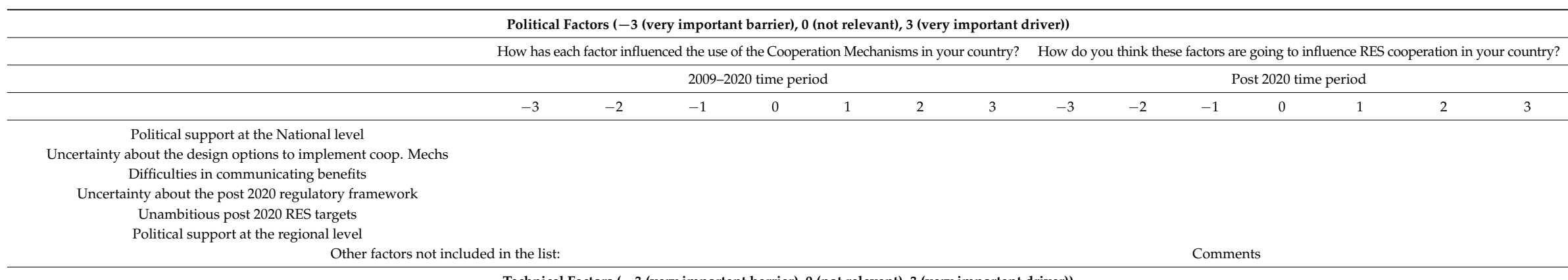

Technical Factors ( -3 (very important barrier), 0 (not relevant), 3 (very important driver)

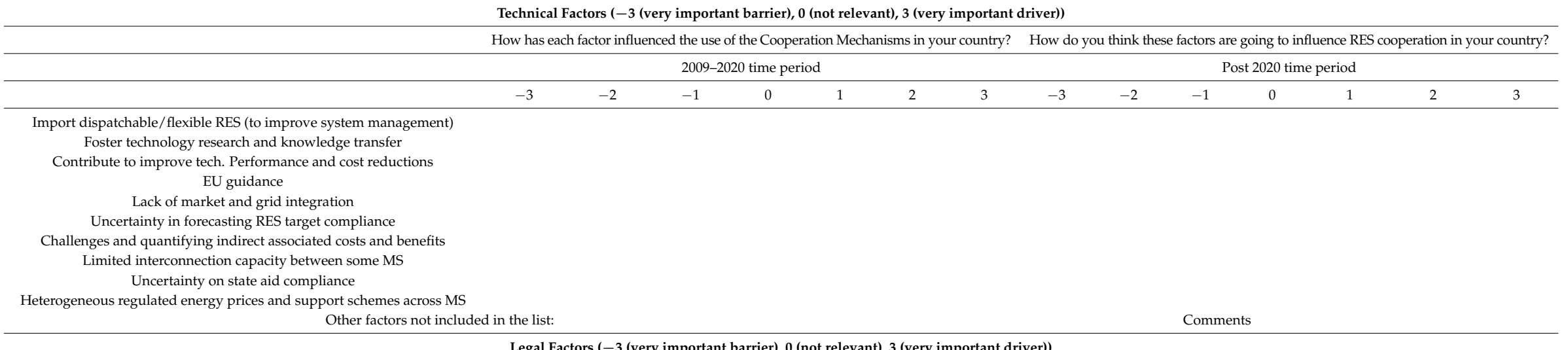

Legal Factors ( -3 (very important barrier), 0 (not relevant), 3 (very important driver))

How has each factor influenced the use of the Cooperation Mechanisms in your country? How do you think these factors are going to influence RES cooperation in your country?

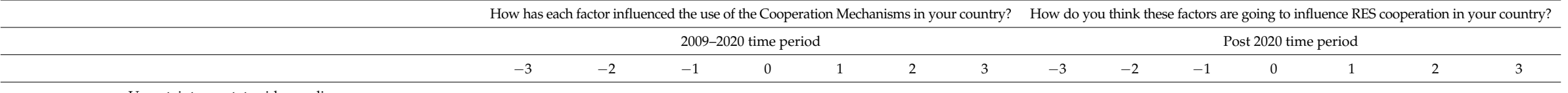

Uncertainty on state aid compliance
Heterogeneous regulated energy prices and support schemes across MS
Obligation to open support schemes

Lack of sanctions for non-compliance with 2020 RES targets 


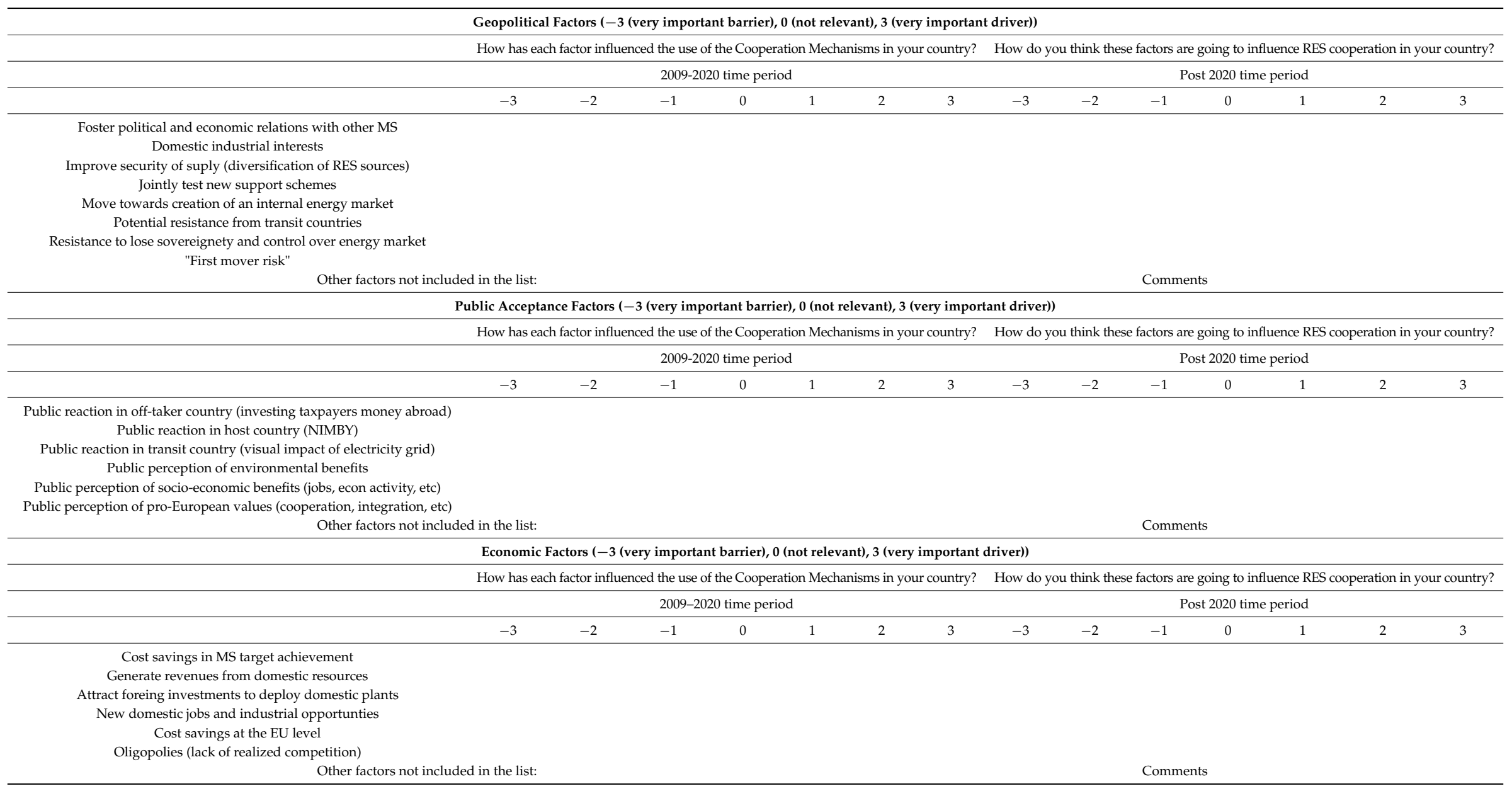


Environmental Factors ( -3 (very important barrier), 0 (not relevant), 3 (very important driver)

\begin{tabular}{l}
\hline \\
\hline
\end{tabular}

Appendix B. Average Results of the Survey Questionnaire Per Disaggregated Factor. Source: Own Elaboration

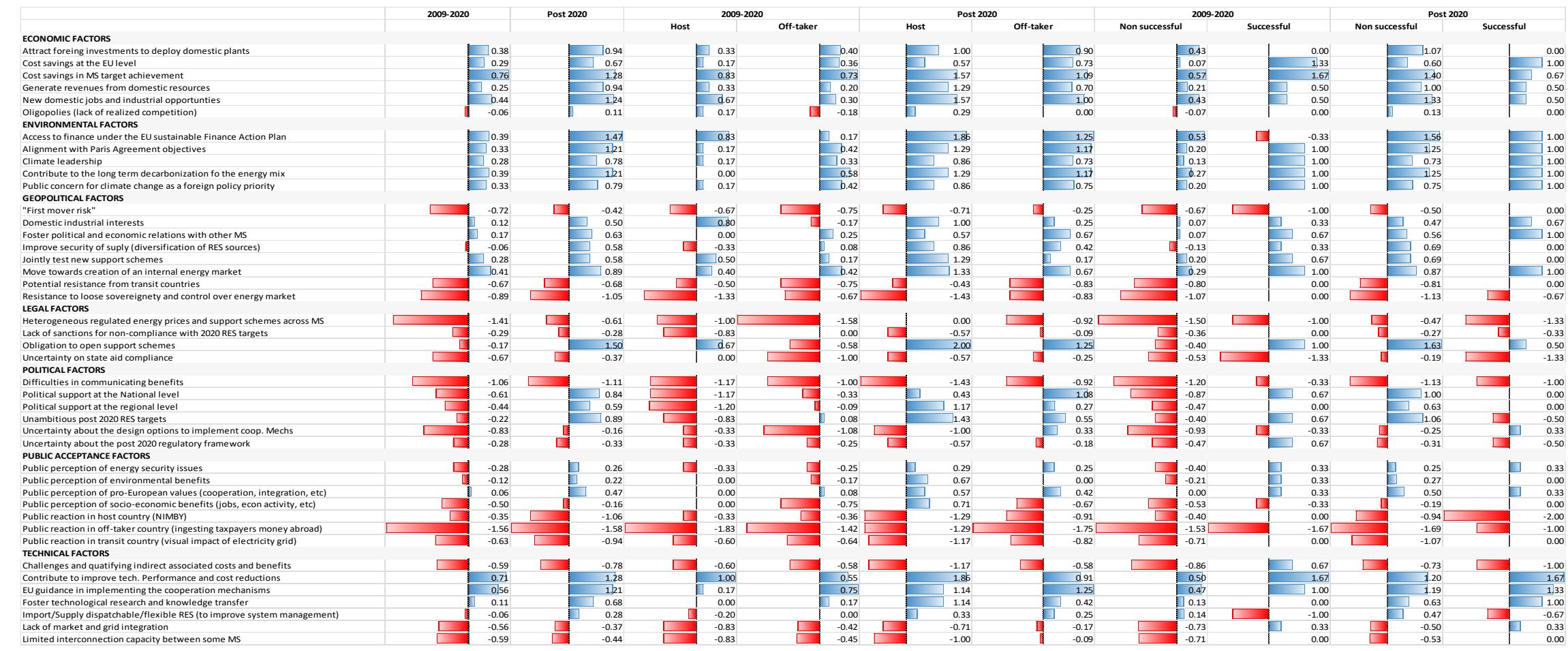




\section{References}

1. Caldés, N.; Lechón, Y.; Rodríguez, I.; Del Río, P. Market Uptake of Solar Thermal Electricity through Cooperation Analysis of the Barriers to the Use of the Cooperation Mechanisms for Renewable Energy in the EU. 2018. Available online: http://mustec.eu/sites/default/files/reports/MUSTECD4. 1_Barriersforcooperationmechanisms.pdf (accessed on 8 November 2018).

2. European Commission DG-ENER. Towards a More Europeanised Approach to Renewables Policy-A Possible Instrument to Support Cross-Border Cooperation on Renewables in the Multiannual Financial Framework Post-2020. In Proceedings of the Expert Consultation Meeting, Brussels, Belgium, 5 March 2018.

3. European Commission. Directive 2009/28/EC of the European Parliament and of the Council of 23 April 2009 on the Promotion of the Use of Energy from Renewable Sources and Amending and Subsequently Repealing Directives 2001/77/EC and 2003/30/EC (Text with EEA Relevance). 2009. Available online: https: / / eur-lex.europa.eu/legal-content/EN/TXT/PDF/?uri=CELEX:32009L0028\&from=EN (accessed on 8 November 2018).

4. Klessmann, C.; Lamers, P.; Ragwitz, M.; Resch, G. Design options for cooperation mechanisms under the new European renewable energy directive. Energy Policy 2010, 38, 4679-4691. [CrossRef]

5. Caldés-Gómez, A.R.; Díaz-Vázquez, N. Promoting Solar Electricity Exports from Southern to Central and Northern European Countries Extremadura Case Study; Publications Office of the European Union: Luxemburg, 2018. [CrossRef]

6. Gephart, M.; Tesnière, L.; Klessmann, C. Driving Regional Cooperation forward in the 2030 Renewable Energy Framework. 2015. Available online: https://us.boell.org/sites/default/files/hbfecofys_regional_ cooperation.pdf (accessed on 8 November 2018).

7. European Commission. SWD(2013) 440 Final Commission Staff Working Document Guidance on the Use of Renewable Energy Cooperation Mechanism Accompanying the Document Communication form the Commission Delivering the Internal Electricity Market and Making the Most of Public Interv. 2013. Available online: http:/ / www.res4less.eu/ (accessed on 8 November 2018).

8. Klessmann, C.; de Visser, E.; Wigand, F.; Gephart, M.; Resch, G.; Busch, S.; Vienna, T.U.; Kitzing, L.; Held, A.; Ragwitz, M.; et al. Cooperation between EU Member States under the RES Directive Cooperation between EU Member States under the RES Directive Task 1 Report. 2014. Available online: www.ecofys.com (accessed on 8 November 2018).

9. European Commisssion. Regulation of the European Parliament and of the Council on the Governance of the Energy Union, amending Directive 94/22/EC, Directive 98/70/EC, Directive 2009/31/EC, Regulation (EC) No 663/2009, Regulation (EC) No 715/2009, Directive 2009/73/EC, Council Directive 2009/119/EC, Directive 2010/31/EU, Directive 2012/27/EU, Directive 2013/30/EU and Council Directive (EU) 2015/652 and Repealing Regulation (EU) No 525/2013. 2017. Available online: https:/ / eur-lex.europa.eu/ resource.html?uri=cellar:ac5d97a8-0319-11e7-8a35-01aa75ed71a1.0024.02/DOC_1\&format=PDF (accessed on 13 December 2018).

10. European Commission. Proposal for a Directive of the European Parliament and of the Council on the Promotion of the Use of Energy from Renewable Sources (Recast) COM(2016) 767 Final/2. 2017. Available online: https://eur-lex.europa.eu/resource.html?uri=cellar:3eb9ae57-faa6-11e6-8a3501aa75ed71a1.0007.02/DOC_1\&format=PDF (accessed on 24 July 2018).

11. European Commission. Proposal for a Regulation of the European Parliament and of the Council Establishing the Connecting Europe Facility and Repealing Regulations. COM(2018) 438 Final. 2018. Available online: https: / /ec.europa.eu/commission/publications/factsheets-long-term-budget-proposals_en (accessed on 8 November 2018).

12. Resch, G.; Liebmann, L.; Ortner, A.; Busch, S.; Panzer, C.; Vienna, T.; del Rio, E.P.; Ragwitz, C.M.; Steinhilber, S.; Klobasa, M.; et al. Design and Impact of a Harmonised Policy for Renewable electricity in Europe Final Report (D7.4) Final Report of the Beyond2020 Project-Approaches for a Harmonisation of RES(-E) Support in Europe Authors. 2014. Available online: www.res-policy-beyond2020.eu (accessed on 8 November 2018).

13. Resch, G.; Ortner, A.; Zehetner, C.; Liebmann, L.; Busch, S.; Welisch, M.; Geipel, J.; del Rio, P.; Ragwitz, M.; Held, A.; et al. Dialogue on a RES policy Framework for 2030 Summary Report Towards2030-Dialogue. 2017. Available online: www.res-policy-beyond2020.eu (accessed on 8 November 2018). 
14. Caldés, N. Bringing Europe and Third Countries Closer Together through Renewable Energies Summary Report. 2015. Available online: http:/ / better-project.net/sites / default/files /BETTER_SummaryReport_0. pdf (accessed on 8 November 2018).

15. Lilliestam, J.; Ellenbeck, S.; Karakosta, C.; Caldés, N. Understanding the absence of renewable electricity imports to the European Union. Int. J. Energy Sect. Manag. 2016, 10, 291-311. [CrossRef]

16. Jacobsen, K.; Thorsten, S.; Pade, H.K.J.L.L.; Schröder, S.T.; Kitzing, L. Cooperation Mechanisms to Achieve Eu Renewable Targets Cooperation Mechanisms to Achieve EU Renewable Targets. Renew. Energy 2014, 63, 345-352. [CrossRef]

17. Browne, D.; O'Mahony, M.; Caulfield, B. How should barriers to alternative fuels and vehicles be classified and potential policies to promote innovative technologies be evaluated? J. Clean. Prod. 2012, 35, 140-151. [CrossRef]

18. Dütschke, E.O.C.; Su-Min, C.; Sala, R. Stakeholder Mapping Report. 2018. Available online: www.mustec.eu (accessed on 10 November 2018).

(C) 2018 by the authors. Licensee MDPI, Basel, Switzerland. This article is an open access article distributed under the terms and conditions of the Creative Commons Attribution (CC BY) license (http://creativecommons.org/licenses/by/4.0/). 